\title{
Knowledge of the Patient's Family Member about Risk Factors and Complications of Coronary Heart Disease
}

\author{
REHANA PARVIN, ${ }^{1}$ KAZI JAHANGIR HOSSAIN,${ }^{2}$ TAMANNA ZAHUR, ${ }^{3}$ MD. RIZWANUL KARIM, ${ }^{4}$ ANM SHAMSUL \\ ISLAM, ${ }^{5}$ BAIZID KHOORSHID RIAZ ${ }^{6}$
}

\begin{abstract}
Objective: To assess knowledge about risk factors and complication of coronary heart disease (CHD).

Method: It was a cross-sectional type of study and research participants were one of the family members of the patient suffering from coronary heart disease. The sample population and unit of sample were households. A total of 147 participants were selected from Inpatient Department of the National Institute of Cardio-Vascular Disease, Sher-e-Bangla Nagar, Dhaka from January 2013 to July 2013 following purposive method of sampling on the basis of defined selection criteria. The research instrument was a pre-tested face-to-face interviewer questionnaire. Knowledge level of the respondents was assessed using Likert type of scale incorporate in the questionnaire.

Results: Most of the research participants $(95.2 \%, n=140)$ were educated and only $4.8 \%(n=07)$ found illiterate. In profession, 29.9\% ( $n=44)$ of the respondents were housewife, 36. I\% $(n=53)$ service holder, $22.4 \%(n=24)$ businessmen and II.6\% $(n=17)$ students. Their average monthly income was Tk. $9149 \pm 108$ and their family income was Tk. $3448 \pm 7$ in average. The mean age of the respondents was $33.1 \pm 6.8$ years of which $76.9 \%(n=113)$ married and rest of them $(23.1 \%, n=34)$ unmarried. Among the respondents, $50.3(n=74)$ were male and $49.7 \%(n=73)$ female respectively. The level of knowledge of the respondents about risk factors and complication of coronary heart disease on the basis of gender, education and occupation was assessed. Of them, $75.5 \%(n=I I I)$ had poor knowledge about risk factors and complication of coronary heart disease, $24.5 \%(n=36)$ satisfactory knowledge and none of them had good knowledge about it which was significantly associated with the level of education, occupational and monthly income status of the respondents.

Conclusion: An individual can modify or avoid many risk factors to prevent CHD or minimize the complication of CHD except age and genetic factors. However, need based health education and behavioral change intervention programs among the risk populations (target populations) and to ensure easy access in public healthcare facilities may be the most important applicable ways to control and/or prevention of CHD in Bangladesh.
\end{abstract}

\section{Introduction}

The coronary heart diseases (CHDs) are lifelong disease. It is the most common form of heart disease and the single most leading cause of premature death all over the world. In general, one in 3 men and one in 4 women die from coronary heart diseases. ${ }^{1}$ More than 36 million people die from noncommunicable diseases (NCDs) every year of which $48 \%$

1. Assistant Professor, Department of Dental Public Health, Marks Dental College, Mirpur, Dhaka.

2. Assistant Professor, Department of Health Education, NIPSOM, Dhaka.

3. Dental Surgeon, UHC Shen Bagh, Noakhali.

4. Assistant Professor, Department of Epidemiology, NIPSOM, Mohakhali, Dhaka.

5. Assistant Professor, Department of Public Health \& Hospital Administration, NIPSOM, Mohakhali, Dhaka.

6. Professor of Public Health \& Hospital Administration, NIPSOM, Mohakhali, Dhaka.

Correspondence: Dr. Rehana Parvin, BDS, MPH. Assistant Professor, Department of Dental Public Health, Marks Dental College, Mirpur, Dhaka. Email: rumu.ddc@gmail.com die from CHDs. About one-fourth deaths occurred before the age of 60 and could have largely been prevented. Premature deaths from CHDs range from 22\% among men and $35 \%$ among women in low-income countries to $8 \%$ among men and 10\% among women in high-income countries. ${ }^{2}$ World Health Organization (WHO) reported five risk factors for $\mathrm{CHD}$ in the top ten leading risks to health. The risk factors are high blood pressure, high cholesterol level in blood, tobacco use, alcohol consumption, and overweight. Other factors associated with higher risk of CHDs include a person's economic and social conditions, also known as the "social determinants of health". ${ }^{3}$ Every year, at least 5 million people die because of tobacco use and about 2.8 million die from being overweight. High cholesterol accounts for roughly 2.6 million deaths and 7.5 million die because of high blood pressure. By 2030, deaths due to NCDs are expected to increase to 52 million per year. ${ }^{4}$

Heart disease is the most common and leading cause of morbidity and mortality in the industrial world as well as 
becoming an increasingly widespread disease in the developing countries. It is the first leading reported causes of death all over the world including Bangladesh. ${ }^{1}$ The topmost risk factors for the development of future heart diseases are increased intake of sodium salt, use of tobacco products, obesity, elevated level of serum cholesterol and lack of physical exercise, and positive genetic predisposition. ${ }^{5-7} \mathrm{In}$ fact, one cannot change one's genetic predisposition, age or gender, but can modify or avoid other risk factors. The risk factors, which can be adjusted or modified through lifestyle advice, are sodium salt intake, tobacco products use, obesity, serum cholesterol level, physical exercise, dietary intake and improper lifestyle functions. ${ }^{8}$ Prevalence of hypertension is $15-20 \%$ among adult population in Bangladesh. ${ }^{9}$ The cardiovascular diseases such as ischemic heart diseases, stroke, and heart failure are one of the major chronic diseases and are the leading cause of death and disability in Bangladesh. High blood pressure is one of the most important direct causes, accounting 50 percent of all heart diseases. Nearly 15 million adults have been suffering from hypertension, among them, $49.0 \%$ in urban and $17.0 \%$ in rural elderly hypertension population are found aware of their high blood pressure of which, only $4.5 \%$ in urban and 3.1\% in rural have found controlled blood pressure. ${ }^{10-11}$

However, awareness about heart diseases particularly coronary heart disease among the patients and family members of the patients is one of the important applicable ways to minimize this human catastrophe. The ultimate aim of this study was to assess knowledge about risk factors and complication of coronary heart diseases among the family member of the coronary heart disease patients to decrease morbidity and mortality due to heart attack (myocardial infarction). It is a grave threat to the public health in Bangladesh, as most of the risk factors are highly prevalent among the community population in Bangladesh. In addition, people living with CHD and high blood pressure are the topmost high-risk subpopulations who become physically disabled all on a sudden. Therefore, the aim of this work was to assess knowledge about risk factors and complication of CHD admitted at the National Institute of Cardio-Vascular Diseases (NICVD), Sher-e-Bangla Nagar, Dhaka. The outcome will, significantly, be supportive and enhance the national preventive activities against coronary heart disease.

\section{Materials and Methods}

\section{Study population}

The research work was a cross-sectional type of study. The research participants were one of the family members of the patient suffering from coronary heart disease. The sample population and unit of sample were households. One of the family members was the respondent from one family. A total of 147 participants were selected from Inpatient Department of the National Institute of Cardio-Vascular Diseases (NICVD), Sher-e-Bangla Nagar, Dhaka from January 2013 to July $2013 .{ }^{12-13}$ They were selected following the purposive method of sampling on the basis of defined selection criteria that included the respondent must have a family member suffering from coronary heart disease irrespective of age, gender, religion and customs, and voluntary participation. The research instrument was a pre-tested face-to-face interviewer questionnaire. The pre-tested participants were excluded from the study population. Trained personnel, other than government employee, briefed the objectives, benefits, risks and burdens of the study to the participants at the bedside of the patients. Only positive respondents were included as research participants consistent with the defined selection criteria. A written informed consent was also taken from each, in maintaining full autonomy, of the participants. They also collected general information following the questionnaire and scheduled for specific data collection date. On the scheduled day, principal author and/or coauthors interviewed the participants in a room individually maintaining the confidentiality strictly. Prior to start of the research work, institutional permission was taken from the director of the NICVD. As the research participants were not vulnerable, the procedures followed for this study were in accordance with the CIOMS guidelines as updated in $2002 .{ }^{14}$ No wedge-compensation was given to the research participant. Knowledge level of the respondents was assessed using Likert type of scale. ${ }^{15-16}$ In the specific part of the questionnaire, there were 25 correct answers about risk factors and complication of coronary heart disease. Four numbers scored for each right answer. The scores were categorized as 20-50, 51-80 and above 80 for poor knowledge, satisfactory knowledge and good knowledge respectively.

\section{Statistical analysis}

A software package of SPSS (version 20.0: SPSS Inc., Chicago, IL, USA) was used to analyze the data. Descriptive statistics were used for all variables. Values were expressed as percentage and mean. Nonparametric Pearson $\mathrm{c}^{2}$ test was carried out for the evaluation of association among the dependent and independent variables of the study.

\section{Results}

Socioeconomic status of the studied population was summarized in the Table I. Most of the research participants $(95.2 \%, n=140)$ were educated and only $4.8 \%(n=07)$ found illiterate. Among the educated participants, 18.3\% ( $\mathrm{n}=17)$ were primary ( $1-8$ class) educated, $25.8 \%(\mathrm{n}=38)$ secondary $\&$ higher secondary (9-12 class), $32.8 \%(\mathrm{n}=48)$ graduate (13-15 class) and $18.3 \%(\mathrm{n}=27)$ masters \& above educated respectively. In profession, $29.9 \%(\mathrm{n}=44)$ of the respondents 
were housewife, $36.1 \%(\mathrm{n}=53)$ service holder, $22.4 \%(\mathrm{n}=24)$ businessmen and $11.6 \%(\mathrm{n}=17)$ students. In monthly income, $40.1 \%(\mathrm{n}=59)$ of the participants had no monthly income, $5.4 \%(\mathrm{n}=08)$ Tk. $1-5$ thousands, $18.3 \%(\mathrm{n}=27)$ Tk. $5-10$ thousands, $17.1 \%(\mathrm{n}=25)$ Tk. $10-15$ thousands, $7.5 \%(\mathrm{n}=11)$ Tk. $15-20$ thousands and $11.6 \%(\mathrm{n}=17)$ had above Tk. 20 thousands. Their average monthly was Tk. $9149 \pm 108$.

Table-I

Socioeconomic status of the respondents $(n=147)$

\begin{tabular}{|c|c|c|c|}
\hline Name of variables & Frequency & Percentage & Mean \pm SD \\
\hline \multicolumn{4}{|l|}{ Education } \\
\hline Illiterate & 7 & 4.8 & \\
\hline $1-8$ class & 27 & 18.3 & \\
\hline $9-12$ class & 38 & 25.8 & \\
\hline 13-15 class & 48 & 32.8 & \\
\hline Above 15 class & 27 & 18.3 & \\
\hline \multicolumn{4}{|l|}{ Occupation } \\
\hline House work & 44 & 29.9 & \\
\hline Service & 53 & 36.1 & \\
\hline Business & 33 & 22.4 & \\
\hline Student & 17 & 11.6 & \\
\hline \multicolumn{4}{|l|}{ Monthly income (Tk) } \\
\hline Nil & 59 & 40.1 & \\
\hline $1000-5000$ & 8 & 5.4 & \\
\hline $5001-10000$ & 27 & 18.3 & $9149 \pm 108$ \\
\hline $10001-15000$ & 25 & 17.1 & \\
\hline $15001-20000$ & 11 & 7.5 & \\
\hline$>20000$ & 17 & 11.6 & \\
\hline \multicolumn{2}{|c|}{ Monthly family income (Tk)Nil } & 105 & 71.5 \\
\hline $1000-5000$ & 15 & 10.2 & \\
\hline $5001-10000$ & 11 & 7.5 & $3448 \pm 6.85$ \\
\hline $10001-15000$ & 3 & 2.0 & \\
\hline $15001-20000$ & 9 & 6.1 & \\
\hline$>20000$ & 4 & 2.7 & \\
\hline \multicolumn{4}{|l|}{ Age in year } \\
\hline $20-30$ & 48 & 32.6 & $33.1 \pm 6.8$ \\
\hline $31-40$ & 79 & 53.8 & \\
\hline $41-50$ & 20 & 13.6 & \\
\hline \multicolumn{4}{|l|}{ Marital status } \\
\hline Unmarried & 34 & 23.1 & \\
\hline Married & 113 & 76.9 & \\
\hline Family members 2-4 & 63 & 42.9 & \\
\hline $5-7$ & 80 & 54.4 & $4.8 \pm 1.5$ \\
\hline $8-10$ & 4 & 2.7 & \\
\hline \multicolumn{4}{|l|}{ Gender } \\
\hline Male & 74 & 24.5 & \\
\hline Female & 73 & 67.3 & \\
\hline
\end{tabular}

In family income, majority of the respondents $(71.5 \%$, $\mathrm{n}=105$ ) had no monthly income and rest of them had income of which $10.2 \%(\mathrm{n}=15)$ Tk. $1-5$ thousands, $7.5 \%(\mathrm{n}=11)$ Tk. 5-10 thousands, $2.0 \%(\mathrm{n}=03)$ Tk. $10-15$ thousands, $6.1 \%$ $(\mathrm{n}=09)$ Tk. $15-20$ thousands and $2.7 \%(\mathrm{n}=04)$ had monthly income above Tk. 20 thousands. The average monthly income of their family was Tk. $3448 \pm 7$. The mean age of the respondents was $33.1 \pm 6.8$ years of which $76.9 \%(n=113)$ married and rest of them $(23.1 \%, n=34)$ unmarried. Of the respondents, $42.9 \%(\mathrm{n}=63)$ had $2-4$ members in family, $54.4 \%(\mathrm{n}=80) 5-7$ members and $2.7 \%(\mathrm{n}=04)$ had $8-10$ family members. Among the respondents, 50.3( $\mathrm{n}=74)$ were male and $49.7 \%(n=73)$ female respectively.

Knowledge of the participants on risk factors of coronary heart disease was summarized in the Table-2. In response to the genetic transmission, $12.9 \%(\mathrm{n}=19)$ mentioned high blood pressure, $11.6 \%(\mathrm{n}=17)$ said high cholesterol in blood, $23.8 \%(n=35)$ expressed diabetes mellitus and $51.7 \%(n=76)$ did not know about it. In response to the addiction and stress, $38.1 \%(\mathrm{n}=56)$ mentioned tobacco smoking, $18.4 \%(\mathrm{n}=27)$ said tobacco smoking and alcohol intake, $17.7 \%(\mathrm{n}=26)$ expressed anxiety, $13.6 \%(\mathrm{n}=20)$ mentioned tobacco smoking and anxiety, and $12.2 \%(\mathrm{n}=18)$ did not know about it. In response to the occupational risk, $55.8 \%(\mathrm{n}=82)$ mentioned service, $25.9 \%(\mathrm{n}=38)$ said hard work, $6.1 \%$ $(n=09)$ expressed business and 12.2\% $(n=18)$ mentioned physical inactivity respectively. In response to dietary habit, $46.9 \%(n=69)$ mentioned oily and fatty foods, $22.4 \%(n=33)$ said oily foods and meat, $9.5 \%(\mathrm{n}=14)$ expressed intake of excess meat, $7.5 \%(\mathrm{n}=11)$ mentioned excess edible salts and $13.6 \%(n=20)$ did not know about it. In response to the risky age group, $11.6 \%(\mathrm{n}=17)$ mentioned $30-40$ years, $21.1 \%(n=31)$ said $41-50$ years, $23.8 \%(n=35)$ expressed 51-60 tears, $28.5 \%(\mathrm{n}=42)$ mentioned $61-70$ years, $8.2 \%$ $(\mathrm{n}=12)$ said above 70 years and $6.8 \%(\mathrm{n}=10)$ did not know about it.

Knowledge of the respondents about complication of coronary heart disease was summarized in the Table-3. Results showed that $10.9 \%(n=16)$ of the respondents mentioned chest pain is the complication of coronary heart disease, $15.6 \%(n=23)$ said heart attack, 3.4\% $(n=05)$ expressed heart failure, $4.1 \%(\mathrm{n}=06)$ mentioned arrhythmia, $21.8 \%(n=32)$ expressed stroke \& paralysis, $8.8 \%(n=13)$ mentioned heart failure \& sudden death, $25.9 \%(\mathrm{n}=38)$ said stroke \& sudden death and 9.5\% ( $\mathrm{n}=14)$ did not know about it. 
Table-II

Knowledge on risk factors of coronary heart disease $(n=147)$

\begin{tabular}{lcc}
\hline Name of the variables & Frequency & Percentage \\
\hline Genetic transmission & & \\
High blood pressure & 19 & 12.9 \\
High cholesterol & 17 & 11.6 \\
Diabetes mellitus & 35 & 23.8 \\
Not known & 76 & 51.7 \\
Addiction and stress & & \\
Smoking & 56 & 38.1 \\
Smoking \& alcohol intake & 27 & 18.4 \\
Anxiety & 26 & 17.7 \\
Smoking \& anxiety & 20 & 13.6 \\
Not known & 18 & 12.2 \\
Occupational risk & & \\
Service & 82 & 55.8 \\
Hard work & 38 & 25.9 \\
Business & 9 & 6.1 \\
Physical inactivity & 18 & 12.2 \\
Dietary habit & & \\
Oily \& fatty food & 69 & 46.9 \\
Oily food \& meatExcess meat & 3314 & 22.49 .5 \\
Excess edible salt & 11 & 7.5 \\
Not known & 20 & 13.6 \\
Risk Age in year & & \\
30-40 & 17 & 11.6 \\
$41-50$ & 31 & 21.1 \\
$51-60$ & 42 & 23.8 \\
61-70 & 12 & 28.5 \\
Above 70 & & 8.2 \\
Not known & 6.8 \\
\hline
\end{tabular}

Table-III

Knowledge on complications of coronary heart disease $(n=147)$

\begin{tabular}{lcc}
\hline Name of the variables & Frequency & Percentage \\
\hline Complications & & \\
Chest pain & 16 & 10.9 \\
Heart attack & 23 & 15.6 \\
Heart failure & 05 & 3.4 \\
Arrhythmia & 06 & 4.1 \\
Stroke \& paralysis & 32 & 21.8 \\
Heart failure \& sudden death & 13 & 8.8 \\
Stroke \& sudden death & 38 & 25.9 \\
Not known & 14 & 9.5 \\
\hline
\end{tabular}

Table-IV summarized the level of knowledge of the respondents about risk factors and complication of coronary heart disease on the basis of gender, education and occupation. Results showed that $75.5 \%(n=111)$ of the respondents were found poor knowledge about risk factors and complication of coronary heart disease, $24.5 \%(n=36)$ satisfactory knowledge and none of them good knowledge about it.

Association (using nonparametric $\mathrm{c}^{2}$ tests) between knowledge of the respondents about risk factors \& complication of coronary heart disease and socioeconomic status (education, occupation, monthly income, family income, age, marital status, family member and gender) was summarized in the Table-5. The knowledge of the respondents on risk factors and complications were found to be significantly $(\mathrm{P}<0.01)$ associated with the level of education and occupational status of the respondents. Risk factors also significantly associated with monthly income of the participants. Others socioeconomic factors did not significantly associated with the risk factors and complication of coronary heart disease.

Table-IV

Level of knowledge of the respondents on risk factor and complication of coronary heart disease $(n=147)$

\begin{tabular}{|c|c|c|c|}
\hline Name of variables & $\begin{array}{c}\text { Poor knowledge } \\
\%(\mathrm{n})\end{array}$ & $\begin{array}{c}\text { Satisfactory } \\
\text { knowledge } \%(n)\end{array}$ & $\begin{array}{c}\text { Good knowledge } \\
\%(\mathrm{n})\end{array}$ \\
\hline \multicolumn{4}{|l|}{ Gender } \\
\hline Male $(n=74)$ & $38.8(57)$ & $11.5(17)$ & Nil \\
\hline Female $(n=73)$ & $36.7(54)$ & $14.0(19)$ & \\
\hline \multicolumn{4}{|l|}{ Education } \\
\hline Illiterate $(n=7)$ & $4.8(7)$ & $0.0(0)$ & Nil \\
\hline Literate (140) & $70.7(104)$ & $24.5(36)$ & \\
\hline \multicolumn{4}{|l|}{ Occupation } \\
\hline Housework $(\mathrm{n}=44)$ & $26.5(39)$ & $3.4(5)$ & Nil \\
\hline Service $(n=53)$ & $21.1(31)$ & $15.0(22)$ & \\
\hline Business $(n=33)$ & $20.4(30)$ & $2.1(3)$ & \\
\hline Student $(\mathrm{n}=17)$ & $7.5(11)$ & $4.1(6)$ & \\
\hline Total $(n=147)$ & $75.5(111)$ & $24.5(36)$ & Nil \\
\hline
\end{tabular}


Table-V

Association of knowledge with socioeconomic status $(n=147)$

\begin{tabular}{lcccccc}
\hline & \multicolumn{3}{c}{ Risk factors } & & \multicolumn{3}{c}{ Complications } \\
\cline { 2 - 5 } & $\begin{array}{c}\text { Not } \\
\text { known } \\
\%(\mathrm{n})\end{array}$ & $\begin{array}{c}\text { Known } \\
\%(\mathrm{n})\end{array}$ & $\chi^{2}$ & $\begin{array}{c}\text { Not } \\
\text { known } \\
\%(\mathrm{n})\end{array}$ & $\begin{array}{c}\text { Known } \\
\%(\mathrm{n})\end{array}$ & $\chi^{2}$ \\
\hline Education & & & $\chi^{2}=11.58$ & & & $\chi^{2}=9.96$ \\
$\quad$ 0-10 class & $28.3(15)$ & $71.7(38)$ & $\mathrm{df}-1$ & $26.4(14)$ & $73.6(39)$ & $\mathrm{df}=1$ \\
$>10$ class & $7.4(7)$ & $92.6(87)$ & $\mathrm{p}=0.001$ & $7.4(7)$ & $92.6(87)$ & $\mathrm{p}=0.002$ \\
Occupation & & & & & & \\
$\quad$ House work & $15.9(7)$ & $84.1(37)$ & $\chi^{2}=13.49$ & $13.6(6)$ & $86.4(38)$ & $\chi^{2}=10.53$ \\
Service & $5.7(3)$ & $94.3(50)$ & $\mathrm{df}=3$ & $3.8(2)$ & $96.2(51)$ & $\mathrm{df}=3$ \\
Business & $33.3(11)$ & $66.7(22)$ & $\mathrm{p}=0.004$ & $27.3(9)$ & $72.7(24)$ & $\mathrm{p}=0.015$ \\
Student & $5.9(1)$ & $94.1(16)$ & & $23.5(4)$ & $76.5(13)$ & \\
No income & $13.6(8)$ & $86.4(51)$ & $\chi^{2}=6.89$ & $15.3(9)$ & $84.7(50)$ & $\chi^{2}=1.75$ \\
$1,000-10,000$ & $27.8 \%(10)$ & $72.2(26)$ & $\mathrm{df}=2$ & $19.4(9)$ & $80.6(29)$ & $\mathrm{df}=2$ \\
$>10,000$ & $7.7 \%(4)$ & $92.3(48)$ & $\mathrm{p}=0.032$ & $9.6(5)$ & $90.4(47)$ & $\mathrm{p}=0.416$ \\
\hline
\end{tabular}

\section{Discussion}

Coronary heart disease (CHD) is the most common form of heart disease and the single most important cause of premature death in the world. By 2020, it is estimated that it will be the major cause of death in all regions of the world. In the Europe, 1 in 3 men and 1 in 4 women die from CHD. However, in Eastern Europe and much of Asia, the rates of CHD are rapidly rising. Disease of the coronary arteries is almost always due to atheroma and its complications, particularly thrombosis. Occasionally, the coronary arteries are involved in other disorders such as aortitis, polyarteritis and other connective tissue disorders. Lifestyle and risk factors modification such as quit of smoking, controlled lipid profile, maintaining an ideal body weight, Mediterraneanstyle diet (less intake of salt-sugar-fat containing diet), taking regular physical exercise, achieving good control of hypertension \& diabetes mellitus and avoiding anxiety \& depression as well as social isolation may all improve the long-term outlook of CHD patients or prevention of CHD. ${ }^{17}$ The present study attempted to address the knowledge one of the family member of the patients admitted in the NICVD about risk factors and complication of CHD.

Most of the respondents were educated. Among them, males were found higher status in degree and above than that of female (not seen in the Table-1). In profession, majority of them had specific jobs such as business, service, house works, etc and had average monthly income of Tk. 10 thousands but a significant group of the respondents (40.1\%) had no monthly income, majority of them had no family income. As a whole, Bangladesh is a densely populated country. Total population is more than 160 million. The trend in population growth, fertility, morbidity, mortality and migration from rural to urban areas are persistently creating hurdles in socioeconomic development. At present, nearly $48.0 \%$ people live below the poverty line. The socioeconomic characteristics of the studied population are consistent with the reported national statistical data. ${ }^{18}$ The possible explanation is that the patriarchal society, religious stigmatism or fundamentalism as well as conventional sociocultural impact may be the important contributing factor for such type of socioeconomic characteristics of the community peoples in Bangladesh. Socio-culture and religious backward tradition may be the unavoidable factors against women empowerment in the community. This trend of socioeconomic status is gradually changing in Bangladesh. However, the socioeconomic status of the studied respondents was found comparatively better than that of others. Education, family income, small family size and relatively better occupation are the leading factors for better socioeconomic status of them.

Coronary heart disease is an adult onset disease. Risk factors of CHD are tobacco products use, physical inactivity, uncontrolled high blood pressure, dietary anomalies such as high intake of salt-sugar-fats containing diet, over-weight \& obesity, uncontrolled diabetes and stress in anxiety. ${ }^{17}$ The complications of $\mathrm{CHD}$ are stable angina, myocardial 
infarction, heart failure and arrhythmias. ${ }^{17}$ Level of knowledge of the respondents about risk factors and complication of CHD were assessed in relation to gender, education and occupations of them. Results showed that majority $(75.5 \%)$ were found poor knowledge, one-fourth $(24.5 \%)$ had satisfactory knowledge and none of them found good knowledge respectively (Table-4). The possible explanation are the control and preventive activities against non-communicable major killer diseases such as heart attack, cancers, stoke and diabetes mellitus in public and/or private health sectors are very much limited in Bangladesh. Easy access in healthcare services both in public as well as private health sectors is still in embryonic stage in rural community all over the country. Most of the adult population particularly in rural community did not know about risk foods for good health. They are very much innocent about healthy lifestyles; smoke and smokeless tobacco products use are highly prevalent among them. In addition, national preventive activities against non-communicable diseases are highly concerned with electronic media, seminar, symposium and workshops etc. Moreover, most of the physicians did not provide preventive message against major killer diseases during treatment of the patients and/or patient's attendance in hospitals and/or private chambers due to their busy practices or commercialization of the healthcare services. There are no systematic procedures for dissemination of preventive messages about coronary heart diseases among the risk-populations in rural as well as urban community in Bangladesh. Most of the target populations are still in dark about the preventive knowledge and exercise of CHD due to inadequate or limited access to public healthcare services. Results also revealed that knowledge of the respondents about risk factors and complication of CHD were found significantly associated with education, occupation and income of the respondents. It is well documented that education, occupation and income significantly affects the level of knowledge of an individuals.

In conclusion, socioeconomic status of the patient's admitted in the NICVD was relatively good and age of respondents was $33.1 \pm 6.8$ years. Level of knowledge about risk factors and complication of CHD were found poor among the threefourth of the respondents, one-fourth had satisfactory knowledge and none of them found good knowledge about it. Knowledge is a multi-factorial variable; no single factor is responsible for acquired perfect knowledge. In fact, an individual can change or modify or avoid many risk factors to prevent CHD or minimize the complication of CHD except age and genetic factors. However, need based health education and behavioral change intervention programs among the risk populations (target populations) and to ensure easy access in public healthcare facilities may be the most important applicable ways to control and/or prevention of CHD and its complications in Bangladesh.

One of the shortcomings of this study is that it only includes NICVD hospital. The reason for this is constrain of fund and inadequate logistic facilities. It will be more scientific if it include public medical college hospitals as well as district hospitals and sample size is to be 400 or above. Further studies are necessary in this field to reveal actual facts. However, so far known, it is the first attempt to address family member of CHD patients in Bangladesh.

\section{Acknowledgements}

Authors thank the Ministry of Science and Information \& Communication Technology, Government of the People's Republic of Bangladesh for partial financial support. Authors also thank the Director and technical staff of the NICVD, Dhaka for their kind assistance.

\section{Conflict of Interest : None}

\section{References}

1. Boon NA, Colledge NR, Walker BR, Hunter JAA. Davidson's Principle \& Practice of Medicine, $20^{\text {th }}$ edition, Elsevier Ltd, New Delhi 2006:581-601.

2. Center for Disease Control and Prevention. http:// www.cdc.gov/features/heartmonth/Date: 09.06.11

3. Emslie C. (2005) Women, men and coronary heart disease: a review of the qualitative literature. Journal of Advanced Nursing 2005;51(4):382-39.

4. Alam MB, Ahasan HN, Islam MZ, Islam MN, Mohammed FR, Mahbub ZMNS, Faiz MA . Pattern of Lipid Profile and Obesity among Secretariat Employees of Bangladesh. Journal of Medicine 2009;10(Suppl):3-6.

5. Zaman M. Cardiovascular Risk Factors: Distribution and Prevalence in a Rural Population of Bangladesh. European Journal of Cardiovascular Prevention \& Rehabilitation 2001;8(2):10.

6. Bangladesh Bureau of Statistics. Statistical Yearbook of Bangladesh 2004. Finance Administration and M/S wing, Dhaka 2005:49-94.

7. Rodriguez-Iturbe B, Romero F. Johonson RJ. Pathophysiological mechanism of salt dependent hypertension. Am J Kidney Dis 2007;50(4):655-72.

8. Lee JH, O'Keefe JH, Bell D, Hensrud DD, Holick MF. Vitamin D deficiency an important, common and easily treatable cardiovascular risk factor. J Am Coll Cardiol 2008; 52(24):1949-56

9. Web page of 'MedLine Plus' http://www.nlm.nih.gov/ medlineplus/ ency/article/007115.htm Date: 02/06/11.

10. Frier BM, Fisher m. Diabetes mellitus. In: Davidson's Principle \& Practice of Medicine, Boon NA, Colledge NR, 
Walker BR eds. 20th edition, Churchill Livingstone, Elsevier 2006:805-08.

11. Segura J, Ruilope LM. Obesity, Essencial hypertension and rennin-angiotensin system. Public Health Nutr 2007;10 (10A):1151-55.

12. Daniel WW. Biostatistics: A foundation for analysis in the health sciences. $5^{\text {th }}$ edition, John Wiley \& Sons New York, USA 1991:129-90.

13. Kothair CR. Research Methodology (Method and Techniques) $2^{\text {nd }}$ edition, Wishwa Prakashan, New Delhi, India 1985:187-222.

14. Council for International Organizations of Medical Sciences (CIOMS). Biomedical research ethics: updating international guidelines. New York: CIOMS Publication; 2002:1-89.
15. Likert scale: http://en.wikipedia.org/wiki/Likert_scale Dated: 18/08/2014.

16. Wuensch, Karl L. (October 4, 2005). "What is a Likert Scale? and How Do You Pronounce 'Likert?". East Carolina University. Retrieved April 30,2009.

17. Newby DE, Grubb NR, Bradbury A. Cardiovascular disease. In: Davidson's Principles \& Practice of Medicine, eds: Walker BR, Colledge RN, Ralston SH, Penman ID; 22 nd edition, Churchill Livingstone, Edinburgh 2014:525-642

18. Bangladesh Bureau of Statistics. Statistical Yearbook of Bangladesh 2008. Finance, administration and M/S wing, Dhaka 2009:9-94. 